\title{
Efficacy and safety of sitagliptin for the treatment of diabetes mellitus complicated by chronic liver injury
}

\author{
Masahiro Asakawa ${ }^{1 *}$, Hiroshi Mitsui ${ }^{2}$, Momoko Akihisa $^{3}$, Tetsuo Sekine ${ }^{1}$, Yoshihiro Niitsu ${ }^{1}$, Arisa Kobayashi ${ }^{1}$, \\ Atsuko Miyake' ${ }^{1}$ Naoaki Hashimoto², Mitsunobu Kawamura ${ }^{1}$ and Yoshihiro Ogawa ${ }^{3}$
}

\begin{abstract}
Aim: To investigate the efficacy and safety of a dipeptidyl peptidase-4 inhibitor, sitagliptin, for treating diabetes mellitus complicated by chronic liver injury.

Methods: Sitagliptin was administered for $13.7 \pm 10.1$ months to 122 patients with DM complicated by chronic liver injury (including 19 patients with liver cirrhosis), and changes in hemoglobin $\mathrm{A} 1 \mathrm{c}(\mathrm{HbA} 1 \mathrm{c})$ and liver enzymes (transaminases, etc.) were evaluated.

Results: $\mathrm{HbA1C}$ was reduced from $8.48 \pm 1.43 \%$ to $7.87 \pm 1.35 \%(\mathrm{P}<0.001)$. Among liver enzymes, alanine aminotransferase (ALT) levels improved from $75.1 \pm 45.2$ to $65.8 \pm 35.8 \mathrm{IU} / \mathrm{L}(P=0.012)$ and gamma-glut amyl-trans peptidase from $155.2 \pm 161.1$ to $133.2 \pm 127.4 \mathrm{IU} / \mathrm{L}(\mathrm{P}=0.044)$. Among the causes of liver injury, non-alcoholic fatty liver disease and alcoholic liver disease both showed the reductions in $\mathrm{HbA1C}$ with no deterioration of liver enzymes. An analysis of 19 patients with liver cirrhosis also showed reductions in $\mathrm{HbA1} \mathrm{c}$ with no deterioration of liver enzymes.
\end{abstract}

Conclusion: It is suggested that sitagliptin can be administered effectively and safely to patients with diabetes mellitus complicated by chronic liver injury, including liver cirrhosis.

Keywords: Dipeptidyl peptidase-4 inhibitor, Sitagliptin, Diabetes mellitus, Chronic liver injury

\section{Background}

The number of patients with diabetes mellitus (DM) is increasing recently in Japan, was estimated at 9.5 million cases in 2012 in reports by Japanese Ministry of Health, Labor and Welfare. Among persons with probable DM, the rates of patients receiving medical treatment are $65.9 \%$ for men and $64.3 \%$ for women, percentages that remain far too low. Dipeptidyl-peptidase 4 (DPP-4) inhibitors have recently been developed as a new viable option for the treatment of DM other than for type 1 DM (T1DM), and the first DPP-4 inhibitor in Japan, sitagliptin, was released in 2009. Subsequently, a variety of

\footnotetext{
*Correspondence: masakawa6238@gmail.com

${ }^{1}$ Department of Endocrinology and Metabolism, Tokyo Teishin Hospital,

2-14-23, Fujimi, Chiyoda-ku, Tokyo 102-0071, Japan

Full list of author information is available at the end of the article
}

DPP-4 inhibitors have been released, so that there were seven DPP-4 inhibitors available by 2013.

The incretin hormones glucagon-like peptide-1 (GLP1) and glucose-dependent insulinotropic polypeptide (GIP) are released from the gastrointestinal tract in response to a meal, which stimulates glucose-dependent insulin production and secretion via specific receptors expressed on the islet $\beta$ cells (Drucker 2002). DPP-4 inhibitors exhibit serum glucose-decreasing action by inhibiting the decomposition of incretin hormones and increasing of insulin secretion (Drucker and Nauck 2006; Ahren 2007; Holst et al. 2009; Omar and Ahren 2014). DPP-4 inhibitors have no effect on weight gain and pose little risk of hypoglycemia following a single administration, which are benefits that have resulted in recently increasing numbers of prescriptions. In addition, DPP-4 inhibitors inhibit glucagon secretion, increase islet cell proliferation, and decrease cell apoptosis in vitro (Farilla

\section{望 Springer}

(c) 2015 Asakawa et al. This article is distributed under the terms of the Creative Commons Attribution 4.0 International License (http://creativecommons.org/licenses/by/4.0/), which permits unrestricted use, distribution, and reproduction in any medium, provided you give appropriate credit to the original author(s) and the source, provide a link to the Creative Commons license, and indicate if changes were made. 
et al. 2002; Li et al. 2003). Since the existence of GLP-1 receptors has been confirmed in several organs other than pancreas, such as stomach, heart, kidney, liver, lung, central nervous system, muscle cells, fat cells, and vascular endothelial cells (Ahren 2004), extra-pancreatic effects of DPP-4 inhibitors are also expected.

Patients with type 2 diabetes mellitus (T2DM) patients often also present with chronic liver injury, and a previous study showed that approximately $80 \%$ of T2DM patients have a fatty liver (Browning et al. 2004). In particular, non-alcoholic fatty liver disease (NAFLD) is a frequent complication of T2DM (Arase et al. 2009), and is the most common form of chronic liver injury in many countries around the world (Angulo 2002). In addition, DM has been suggested to enhance the development of hepatocellular carcinoma in patients with chronic hepatitis C (Kawamura et al. 2008; Veldt et al. 2008). As stated above, DM is closely related to chronic liver injury. On the other hand, since most oral hypoglycemic agents are metabolized in the liver and may induce liver damage, the treatment of T2DM patients with chronic liver injury is often difficult (Nauck et al. 2007).

Since the DPP-4 inhibitor sitagliptin is minimally metabolized in the liver and over $80 \%$ is excreted in an unaltered state in the urine (Drucker and Nauck 2006), it is expected that the pharmacokinetic of sitagliptin will have few negative effects even in patients with chronic liver injury. Although previous studies have shown the efficacy and safety of sitagliptin in a few patients with NAFLD or chronic hepatitis C (Iwasaki et al. 2011; Arase et al. 2013; Arase et al. 2011), the investigations remain insufficient.

In this study, we investigated the efficacy and safety of sitagliptin in patients with non-T1DM complicated by chronic liver injury.

\section{Methods \\ Patients}

We investigated previous prescriptions written in Tokyo Teishin Hospital, and found 1,148 patients with DM other than T1DM who were administered sitagliptin (50 mg/day) between April 2010, and September 2013. Among them, the DM of 122 patients was complicated by liver injury at the start of sitagliptin administration. We regarded a patient to have liver injury based on the following clinical data: (1) elevation of serum aspartate aminotransferase (AST) and/or alanine aminotransferase (ALT) levels, or (2) the existence of primary liver disease associated with thrombocytopenia with platelet counts below $100,000 / \mu \mathrm{L}$. The causes of liver injury were assessed comprehensively from past medical histories, drinking habits (daily alcohol consumption above or below $20 \mathrm{~g}$ ), clinical data such as viral markers of hepatitis, liver fibrosis markers, antinuclear antibodies, and imaging views by abdominal ultrasonography and/or computed tomography (CT). NAFLD was diagnosed for patients with fatty liver alleged by CT and/or ultrasound, with daily alcohol consumption below $20 \mathrm{~g}$, and with negative hepatitis $B$ and $C$ virus and autoantibodies. Alcoholic liver disease (ALD) was diagnosed for patients with elevated liver enzymes, with daily alcohol consumption above $20 \mathrm{~g}$, and with negative hepatitis $\mathrm{B}$ and $\mathrm{C}$ virus and autoantibodies. Chronic hepatitis $\mathrm{C}$ ( $\mathrm{C}-$ $\mathrm{CH}$ ) was diagnosed for patients with positive hepatitis $\mathrm{C}$ virus markers; antibody for hepatitis $C$ virus or positive hepatitis $\mathrm{C}$ virus' RNA. Autoimmune hepatitis (AIH) was diagnosed for patient with positive anti-nuclear antibody, elevated immunoglobulin G (IgG), negative anti-mitochondrial antibody, and with chronic hepatitis characterized by interface hepatitis or infiltration of plasma cells confirmed by liver biopsy. Moreover, patients with liver cirrhosis were diagnosed based on findings of CT and/ or ultrasound, which showed rough liver surface, rough echoic levels in liver, dull liver edge, splenomegaly, and ascites, and blood tests, which showed thrombocytopenia, and reduced biosynthetic capacity such as albumin, prothrombin, total cholesterol, and cholinesterase.

\section{Clinical and laboratory evaluation}

We conducted retrospective investigation of the 122 patients based on the clinical data in their medical records at the start of sitagliptin administration (pretreatment) and at the end of the study period (September 2013) (post-treatment). All included patients received sitagliptin for a minimum of 3 months. If sitagliptin administration was ceased for some reason prior to September 2013, the data at the time of cessation were used as the post-treatment values. Serum levels of AST, ALT, gamma-glut amyl-trans peptidase $(\gamma \mathrm{GT})$ and hemoglobin A1c (HbA1c, NGSP value) were compared pre- and post-treatment.

In addition, we investigated the clinical data classified by the type of chronic liver injury: the NAFLD group and ALD group. We also investigated the clinical data for the LC group independently.

\section{Statistical analysis}

SPSS ver. 20 for Windows software was used to perform statistical analysis. Data are expressed as mean \pm SD unless indicated otherwise. The paired $t$ test was used to compare the pre-treatment and post-treatment clinical data. A $p$ value $<0.05$ was considered statistically significant. 


\section{Results}

\section{Characteristics of enrolled patients}

Table 1 shows the characteristics before follow-up of the 122 patients (93 men and 29 women: mean age, $58.5 \pm 13.9$ ) with DM complicated by chronic liver injury. Nineteen patients were diagnosed with LC, 10 with ALD, 6 with $\mathrm{C}-\mathrm{CH}, 2$ with NAFLD and one with AIH. Two patients with NAFLD were considered to develop nonalcoholic steatohepatitis (NASH), which shows the ballooning of hepatocytes, proliferation of inflammatory cells, and hepatic fibrosis in histology. LC patients were graded by their Child-Pugh score (Cholongitas et al. 2005), which suggests liver functional reserves, with 12 classified as Child-Pugh A, 5 as Child-Pugh B, and 2 as Child-Pugh C.

The causes of chronic liver injury in the remaining 103 patients (non-LC group) were NAFLD in 62 patients, ALD in 17 patients, $\mathrm{C}-\mathrm{CH}$ in 3 patients and autoimmune hepatitis $(\mathrm{AIH})$ in 1 patient. As one patient with $\mathrm{AIH}$ was treated by prednisolone, her DM was possibly exacerbated by steroid therapy. The causes of chronic liver injury in 20 patients were unknown due to insufficient clinical data.

Pre follow-up, 67 patients were receiving no oral hypoglycemic drugs; 25 patients were receiving one drug (biguanide (BG) in 9 patients, sulfonylurea (SU) in 8 patients, insulin in 7 patients, and thiazolidine (TZD) in one patient); 26 patients were receiving two drugs (SU and BG in 16 patients, insulin and BG in 3 patients, TZD and BG in 3 patients, insulin and SU in 2 patients, and SU and $\alpha$-glucosidase inhibitor ( $\alpha$-GI) in 2 patients); 4 patients were receiving three drugs (insulin, BG and $\alpha-G I$ in 1 patient, insulin, SU and $\alpha$-GI in 1 patient, SU, BG and TZD in 1 patient, and SU, BG and $\alpha-$ GI in 1 patient).

\section{Changes in clinical data}

The duration of sitagliptin administration was $13.7 \pm 10.1$ months on average. The average HbA1c levels decreased from $8.48 \pm 1.43$ to $7.87 \pm 1.35 \%$ ( $<<0.001)$. Among liver enzymes, average AST levels underwent no significant change (from $56.0 \pm 25.8 \mathrm{IU} / \mathrm{L}$ to $56.9 \pm 27.6 \mathrm{IU} / \mathrm{L}$, $\mathrm{P}=0.718$ ), while average ALT levels decreased (from $75.1 \pm 45.2$ to $65.8 \pm 35.8 \mathrm{IU} / \mathrm{L}, \mathrm{P}=0.012)$, and average $\gamma$ GT levels decreased (from $155.2 \pm 161.1$ to $133.2 \pm 127.4 \mathrm{IU} / \mathrm{L}, \mathrm{P}=0.044$ ) (Figures 1, 2).

As shown in Table 2, a reduction in $\mathrm{HbA1c}$ without any deterioration in liver enzymes was observed for patients whose liver injury was classified as either NAFLD or ALD (non-LC), although the reduction in HbA1c in the ALD group was not statistically significant. An analysis of patients with LC also showed a reduction in HbA1c without a deterioration in liver enzymes (Table 3).

\section{Safety of sitagliptin}

Three patients developed mild hypoglycemia (one patient in the NAFLD group receiving sulfonylurea, one patient in the ALD group receiving insulin, and 1 patient in the LC group receiving sulfonylurea), but no severe cases of hypoglycemia were seen in this study. Four patients died during the follow-up period; one was due to myeloproliferative disease (71 year-old male in the LC group), one was due to brain hemorrhage (77 year-old male in the LC group), one was due to pneumonia (88 year-old male in the NAFLD group), and one was due to rupture of a

Table 1 Baseline characteristics

\begin{tabular}{|c|c|c|c|c|c|}
\hline & \multirow[t]{2}{*}{ Total } & \multicolumn{3}{|l|}{ Non LC } & \multirow[t]{2}{*}{ LC } \\
\hline & & NAFLD & ALD & $\mathrm{C}-\mathrm{CH}$ & \\
\hline$n$ & 122 & 62 & 17 & 3 & 19 \\
\hline Age (years) & $58.5 \pm 13.9$ & $55.9 \pm 15.4$ & $60.1 \pm 10.9$ & $53.6 \pm 14.8$ & $66.4 \pm 8.7$ \\
\hline Sex (male/female) & $93 / 29$ & $48 / 14$ & $16 / 1$ & $0 / 3$ & $13 / 6$ \\
\hline Duration of diabetes (years) & $9.2 \pm 7.5$ & $8.0 \pm 5.6$ & $9.0 \pm 6.9$ & $10.3 \pm 9.5$ & $9.0 \pm 4.8$ \\
\hline $\mathrm{BMI}\left(\mathrm{kg} / \mathrm{m}^{2}\right)$ & $26.9 \pm 5.4$ & $28.0 \pm 5.3$ & $26.8 \pm 5.4$ & $29.3 \pm 15.8$ & $23.9 \pm 2.8$ \\
\hline Platelet $(\times 104 / \mu \mathrm{L})$ & $18.3 \pm 6.5$ & $20.3 \pm 5.7$ & $19.0 \pm 4.6$ & $20.5 \pm 6.6$ & $9.3 \pm 4.0$ \\
\hline $\mathrm{HbA1c}(\%)$ & $8.48 \pm 1.43$ & $8.57 \pm 1.23$ & $8.29 \pm 1.77$ & $9.76 \pm 2.70$ & $8.12 \pm 1.29$ \\
\hline AST (IU/L) & $56.0 \pm 25.8$ & $52.7 \pm 25.3$ & $66.5 \pm 28.3$ & $71.0 \pm 26.2$ & $60.4 \pm 30.9$ \\
\hline $\mathrm{ALT}(\mathrm{IU} / \mathrm{L})$ & $75.1 \pm 45.2$ & $79.2 \pm 45.4$ & $88.0 \pm 67.4$ & $94.0 \pm 10.8$ & $49.5 \pm 28.4$ \\
\hline$\gamma \mathrm{GT}(\mathrm{IU} / \mathrm{L})$ & $155.2 \pm 161.1$ & $112.0 \pm 80.4$ & $232.8 \pm 144.7$ & $92.3 \pm 47.4$ & $277.6 \pm 310.4$ \\
\hline Duration of sitagliptin dosing (months) & $13.7 \pm 10.1$ & $15.2 \pm 10.0$ & $10.6 \pm 9.1$ & $7.3 \pm 6.6$ & $9.1 \pm 9.6$ \\
\hline
\end{tabular}

The data represent the mean \pm SD.

$\mathrm{AlH}$ in 1 patient and unknown cause in 20 patients in addition to the data above.

$H b A 1 c$ hemoglobin A1c, AST aspartate aminotransferase, ALT alanin aminotransferase. 


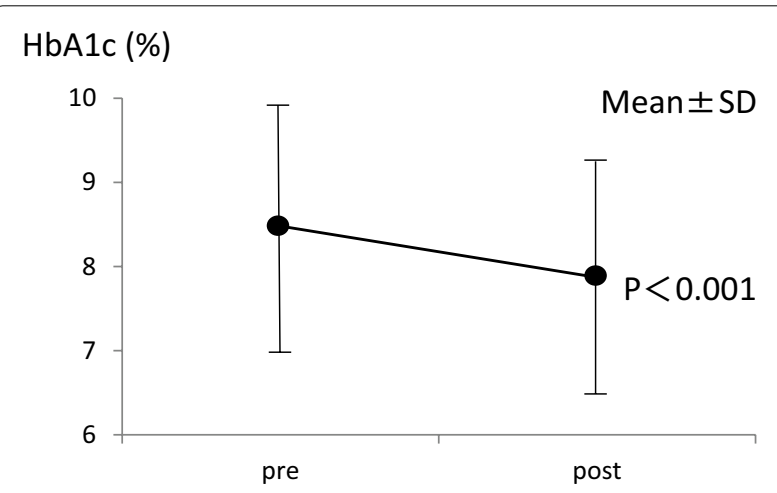

\section{AST (IU/L)}

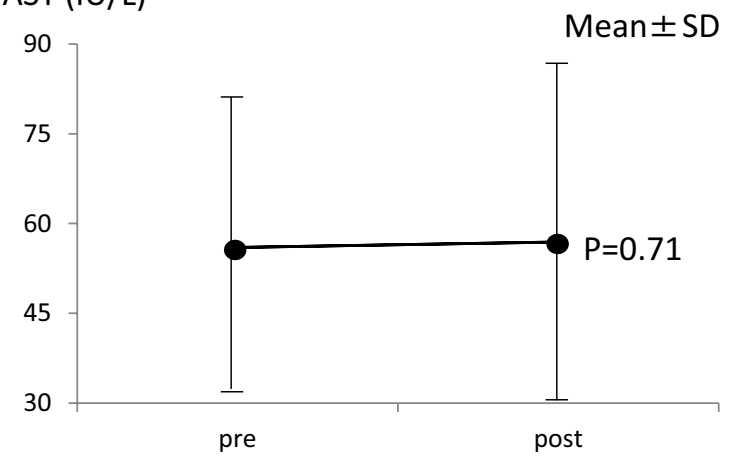

Figure 1 Changes in $\mathrm{HbA} 1 \mathrm{c}$ and AST in all patients.

hepatocellular carcinoma (65 year-old male in the LC group). We cannot deny the relationship between rupture of a hepatocellular carcinoma and sitagliptin administration, because recently it has been demonstrated that CXCR4/CXCL12 axis exerts a variety of functions at different steps of hepatocellular carcinoma progression, and CXCL12 may be inactivated by DPP-4 cleavage (Ismael et al. 2014). No other adverse events developed, and no patients stopped sitagliptin treatment due to adverse effects.

\section{Discussion}

We have described the efficacy and safety of sitagliptin as a treatment for patients with DM complicated by chronic liver injury. The present study shows that the administration of sitagliptin for an average of 13.7 months resulted in $0.61 \%$ decrease in the level of HbA1c, as well as decreased ALT and $\gamma$ GT levels in 122 patients including 19 patients with LC. The ALT and $\gamma$ GT levels did not decrease significantly when analyzed with respect to the causes of chronic liver injury, but the data suggest at least that no deterioration of AST, ALT and $\gamma$ GT levels was caused by sitagliptin. In particular, this study can be considered valuable in

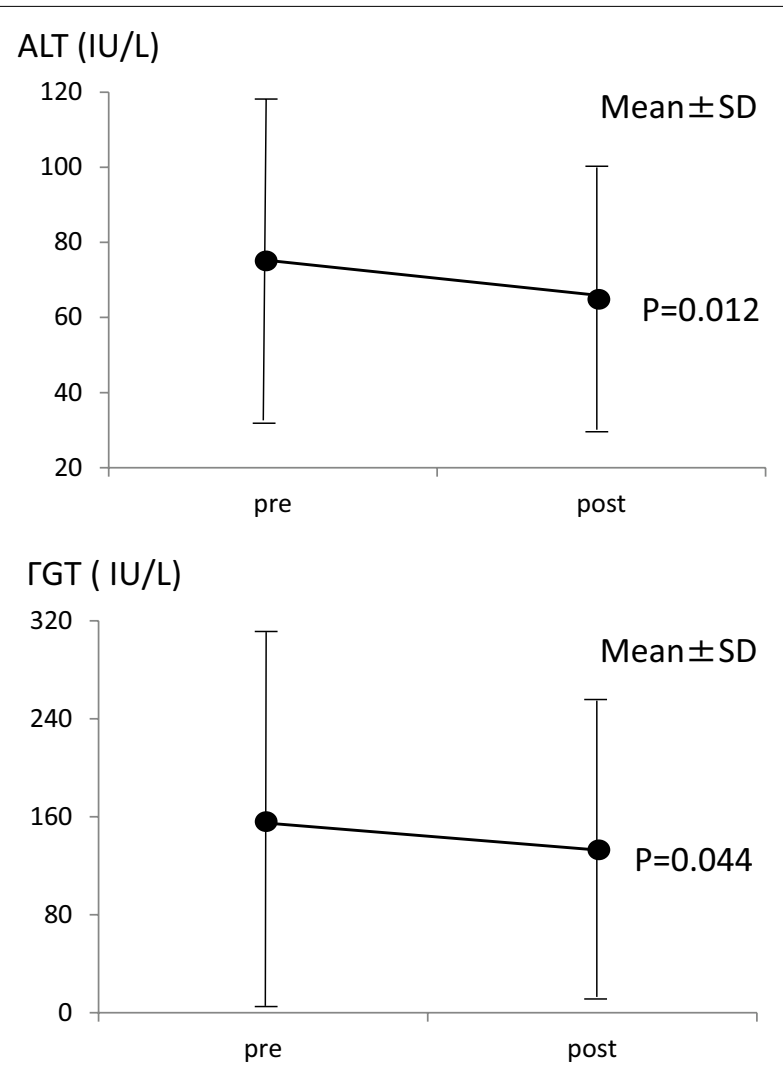

Figure 2 Changes in ALT and $\gamma \mathrm{GT}$ in all patients.

demonstrating that sitagliptin decreased HbA1c levels without causing any deterioration in liver enzymes even in patients with LC.

Recently, several studies have examined the relationships between DPP-4 or incretin hormones and liver. DPP-4 plays a role in fibroblast activation in the liver by activating hepatic stellate cells (Piazza et al. 1989; Levy et al. 1999), while sitagliptin, a DPP-4 inhibitor, attenuates hepatic fibrosis by suppressing activated hepatic stellate cells in rats (Kaji et al. 2014). The GLP-1 receptor is present on human hepatocytes and has been shown to play a direct role in decreasing hepatic steatosis in vitro by modulating components of the insulin signaling pathway (Gupta et al. 2010). GLP-1 suppresses hepatic lipogenesis by activating the cAMP-activated protein kinase (AMPK) pathway (Shlomo et al. 2011). Although the investigations in vivo are still insufficient, the data suggest that DPP-4 inhibitors and GLP-1 receptor agonists may improve hepatic steatosis and suppress the progression of hepatic fibrosis.

NAFLD is the leading cause of chronic liver injury in T2DM, as was seen in this study. NAFLD is considered to be a hepatic manifestation of the metabolic syndrome, 
Table 2 Changes in clinical data of diabetes mellitus complicated by chronic liver injury (NAFLD and ALD)

\begin{tabular}{|c|c|c|c|c|c|c|c|}
\hline & \multicolumn{3}{|c|}{ NAFLD group $(n=62)$} & & \multicolumn{3}{|c|}{ ALD group $(n=17)$} \\
\hline & Pre-treatment & Post-treatment & $P$ value & & Pre-treatment & Post-treatment & $P$ value \\
\hline $\mathrm{HbA} 1 \mathrm{c}(\%)$ & $8.57 \pm 1.23$ & $7.99 \pm 1.22$ & $<0.001$ & HbA1c (\%) & $8.29 \pm 1.77$ & $7.79 \pm 1.42$ & 0.099 \\
\hline AST (IU/L) & $52.7 \pm 25.3$ & $55.5 \pm 29.4$ & 0.491 & AST (IU/L) & $66.5 \pm 28.3$ & $63.1 \pm 22.0$ & 0.563 \\
\hline ALT (IU/L) & $79.2 \pm 45.4$ & $74.7 \pm 41.5$ & 0.398 & ALT (IU/L) & $88.0 \pm 67.4$ & $63.0 \pm 26.1$ & 0.083 \\
\hline$\gamma \mathrm{GT}(\mathrm{IU} / \mathrm{L})$ & $112.0 \pm 80.4$ & $115.4 \pm 95.7$ & 0.713 & $\gamma \mathrm{GT}(\mathrm{IU} / \mathrm{L})$ & $232.8 \pm 144.7$ & $163.8 \pm 102.3$ & 0.023 \\
\hline
\end{tabular}

Table 3 Changes in clinical data of diabetes mellitus complicated by liver cirrhosis

\begin{tabular}{|c|c|c|c|}
\hline & \multicolumn{3}{|c|}{ LC group $(n=19)$} \\
\hline & Pre-treatment & Post-treatment & $P$ value \\
\hline HbA1c (\%) & $8.12 \pm 1.29$ & $7.38 \pm 1.24$ & 0.006 \\
\hline AST (IU/L) & $60.4 \pm 30.9$ & $64.5 \pm 33.3$ & 0.628 \\
\hline $\mathrm{ALT}(\mathrm{IU} / \mathrm{L})$ & $49.5 \pm 28.4$ & $44.5 \pm 24.3$ & 0.483 \\
\hline$\gamma \mathrm{GT}(\mathrm{IU} / \mathrm{L})$ & $277.6 \pm 310.4$ & $212.7 \pm 277.5$ & 0.237 \\
\hline
\end{tabular}

and is particularly associated with insulin resistance, obesity, hypertension, and abnormalities in glucose and lipid metabolism (Chitturi et al. 2002). The histological changes seen in NAFLD range over a wide spectrum, extending from simple steatosis, which is generally nonprogressive, to NASH, liver cirrhosis and liver failure, and, sometimes, even hepatocellular carcinoma (Ludwig et al. 1980). It is expected that DPP-4 inhibitors and GLP-1 receptor agonists will be especially effective in treating T2DM patients with NAFLD, because several studies have shown that the serum concentration of DPP-4 is high in NAFLD patients where it is related to insulin resistance (Firneisz et al. 2010), and that the expression of GLP-1 receptor is reduced in NASH patients (Ding et al. 2006). A previous study showed that the administration of sitagliptin ( $50 \mathrm{mg} /$ day) for 16 weeks resulted in significant decreases in serum HbA1c, AST, ALT and $\gamma$ GT levels in 30 NAFLD patients with T2DM (Iwasaki et al. 2011), a finding that suggests sitagliptin improves the effects of fatty liver. Although significant decreases in the serum levels of AST, ALT and $\gamma$ GT were not found for 62 NAFLD patients in our study, further investigations are necessary to assess the efficacy of sitagliptin in NAFLD patients. Although our study included NAFLD patients co-treated with thiazolidine, which has the efficacy of improving liver histology and fibrosis in NASH patients (Boettcher et al. 2012), the conclusion has not been changed even if these patients were excluded from the analysis because the number of these patients was only 3.
We also investigated the efficacy and safety of sitagliptin also in ALD and LC patients. In particular, efficacy and safety of sitagliptin in LC patients have not been sufficiently investigated until now. LC can be defined as the end stage of chronic liver disease with progressive fibrosis, and can be fatal due to the development of hepatocellular carcinoma or liver failure (Bataller and Brenner 2005). It is often difficult to treat patients with T2DM complicated by liver diseases using oral hypoglycemic agents, because most existing oral hypoglycemic agents are metabolized in the liver, which may lead to an increase in hypoglycemic episodes or a deterioration of liver function. Since the DPP-4 inhibitor sitagliptin is only minimally metabolized in liver with over $80 \%$ excreted intact in urine (Drucker and Nauck 2006), it is expected that sitagliptin will reduce serum glucose levels without causing a deterioration in liver enzymes even in LC patients. This study investigated 19 patients with LC including those with severely impaired hepatic functional reserves (5 patients classified as Child-Pugh B and 2 patients as Child-Pugh C), with no apparent deterioration in liver enzymes. Although the number of patients is low, the result can be considered valuable. Since a previous study showed that sitagliptin attenuates hepatic fibrosis by suppressing activated hepatic stellate cells in vitro (Kaji et al. 2014), it is worthy investigating further whether sitagliptin suppresses the progression of hepatic fibrosis in LC patients.

Although we believe our findings to be valuable, the limitations of this study are as follows. First, this study is a retrospective, observational study, and the duration of sitagliptin administration was not the same in all cases. Second, the number of patients was insufficient (122 patients), and, moreover, the causes of chronic liver injury in 20 patients were unknown due to the lack of sufficient clinical data. Third, we only assessed liver enzymes such as serum AST, ALT and $\gamma$ GT levels, and the assessments for true liver function, such as serum albumin, prothrombin, cholinesterase and bilirubin, are insufficient. Fourth, the degree of hepatic fibrosis was not assessed using objective markers such as serum hyaluronic acid or type 
IV collagen 7S domain, or other modalities such as Fibroscan. Further investigations are necessary to assess efficacy and safety of sitagliptin for the treatment of patients with DM complicated by chronic liver injury.

\section{Conclusion}

It is suggested that sitagliptin can be administered effectively and safely to patients with diabetes mellitus complicated by chronic liver injury, including those with liver cirrhosis.

\begin{abstract}
Abbreviations
DM: diabetes mellitus; T2DM: type 2 diabetes mellitus; DPP-4: dipeptidyl peptidase-4; GLP-1: glucagon-like peptide-1; GIP: glucose-dependent insulinotropic polypeptide; NAFLD: non-alcoholic fatty liver disease; ALD: alcoholic liver disease; $\mathrm{C}-\mathrm{CH}$ : chronic hepatitis C; NASH: non-alcoholic steatohepatitis; LC: Iiver cirrhosis; AlH: autoimmune hepatitis; SU: sulfonylurea; BG: biguanide; TZD: thiazolidine; $\alpha$-Gl: $\alpha$-glucosidase inhibitor; HbA1c: hemoglobin A1c; AST: aspartate aminotransferase; ALT: alanine aminotranseferase; $\gamma \mathrm{GT}$ : gamma-glut amyl-trans peptidase.
\end{abstract}

\section{Authors' contributions}

MA drafted the manuscript. HM, MA, TS, YN, AK, AM, and NH contributed data collection and argued the contents of the manuscript. MK designed the project and revised the manuscript. YO gave final approval of the version to be published. All authors read and approved the final manuscript.

\section{Author details \\ 1 Department of Endocrinology and Metabolism, Tokyo Teishin Hospital, 2-14-23, Fujimi, Chiyoda-ku, Tokyo 102-0071, Japan. ${ }^{2}$ Department of Gastroen- terology, Tokyo Teishin Hospital, 2-14-23, Fujimi, Chiyoda-ku, Tokyo 102-0071, Japan. ${ }^{3}$ Department of Molecular Endocrinology and Metabolism, Tokyo Medical and Dental University Hospital, 1-5-45, Yushima, Bunkyo-ku, Tokyo 113-8510, Japan.}

\section{Acknowledgements}

We thank Dr. Margaret Dooley Ohto (Tokyo Metropolitan Geriatric Hospital, 35-2 Sakae-cho, Itabashi-ku, Tokyo, Japan) for assistance in the preparation of this manuscript.

\section{Sources of funding}

All of authors have no sources of funding.

\section{Compliance with ethical guidelines}

\section{Competing interests}

The authors declare that they have no competing interests.

\section{Ethical approval}

This study was approved by the Ethics Committee of Tokyo Teishin Hospital.

Received: 28 February 2015 Accepted: 17 June 2015

Published online: 15 July 2015

\section{References}

Ahren B (2004) GLP-1 and extra-islet effects. Horm Metab Res 36:842-845

Ahren B (2007) Dipeptidyl peptidase-4 inhibitors: clinical data and clinical manifestations. Diabetes Care 30:1344-1350

Angulo P (2002) Non-alcoholic fatty liver diseases. N Engl J Med 346:1221-1231

Arase Y, Suzuki F, Ikeda K, Kumada H, Tsuji H, Kobayashi T (2009) Multivariate analysis of risk factors for the development of type 2 diabetes in nonalcoholic fatty liver disease. J Gastroenterol 44:1064-1070
Arase Y, Suzuki F, Kobayashi M, Suzuki Y, Kawamura Y, Matsumoto N et al (2011) Efficacy and safety in sitagliptin therapy for diabetes complicated by chronic liver disease caused by hepatitis C virus. Hepatol Res 41:524-529

Arase Y, Kawamura Y, Seko Y, Kobayashi M, Suzuki F, Suzuki Y et al (2013) Efficacy and safety in sitagliptin therapy for diabetes complicated by nonalcoholic fatty liver disease. Hepatol Res 43:1163-1168

Bataller R, Brenner DA (2005) Liver cirrhosis. J Clin Invest 115:209-218

Boettcher E, Csako G, Pucino F, Wesley R, Loomba R (2012) Meta-analysis: pioglitazone improves liver histology and fibrosis in patients with nonalcoholic steatohepatitis. Aliment Pharmacol Ther 35:66-75

Browning JD, Szczepaniak LS, Dobbins R, Nuremberg P, Horton JD, Cohen JC et al (2004) Prevalence of hepatic steatosis in an urban population in the United States: impact of ethnicity. Hepatology 40:1387-1395

Chitturi S, Abeygunasekera S, Farrell GC, Holmes-Walker J, Hui JM, Fung C et a (2002) NASH and insulin resistance: insulin hypersecretion and specific association with the insulin resistence syndrome. Hepatology 35:373-379

Cholongitas E, Papatheodoridis GV, Vangeli M, Terreni N, Patch D, Burroughs AK (2005) Systematic review: the model for end-stage liver disease - should it replace Child-Pugh's classification for assessing prognosis in cirrhosis? Aliment Pharmacol Ther 22:1079-1089

Ding X, Saxena NK, Lin S, Gupta NA, Anania FA (2006) Exendin-4, a glucagonlike protein-1 (GLP-1) receptor agonist, reverses hepatic steatosis in ob/ ob mice. Hepatology 43:173-181

Drucker DJ (2002) Biological actions and therapeutic potential of the glucagon-like peptides. Gastroenterology 122:531-544

Drucker DJ, Nauck MA (2006) The incretin system: glucagon-like peptide-1 receptor agonists and dipeptidyl peptidase-4 inhibitors in type 2 diabetes. Lancet 368:1696-1705

Farilla L, Hui H, Bertolotto C, Kang E, Bulotta A, Di Mario U et al (2002) Glucagon-like peptide-1 promotes islet cell growth and inhibits apoptosis in Zucker diabetic rats. Endocrinology 143:4397-4408

Firneisz G, Varga T, Lengyel G, Feher J, Ghyczy D, Wichmann B et al (2010) Serum dipeptidyl peptidase-4 activity in insulin resistant patients with non-alcoholic fatty liver disease: a novel liver disease biomarker. PLoS One 5(8):e12226

Gupta NA, Mells J, Dunham RM, Grakoui A, Handy J, Saxena NK et al (2010) Glucagon-like peptide-1 receptor is present on human hepatocytes and has a direct role in decreasing hepatic steatosis in vitro by modulating elements of the insulin signaling pathway. Hepatology 51:1584-1592

Holst JJ, Vilsboll T, Deacon CF (2009) The incretin system and its role in type 2 diabetes. Mol Cell Endocrinol 297:127-136

Ismael G, Maria ER, Valerie P, Sandrine F, Paula M, Eric R (2014) Insights on the CXCL12-CXCR4 axis in hepatocellular carcinoma carcinogenesis. Am J Transl Res 6(4):340-352

Iwasaki T, Yoneda M, Inamori M, Shirakawa J, Higurashi T, Maeda S et al (2011) Sitagliptin as a novel treatment agent for non-alcoholic fatty liver disease patients with type 2 diabetes mellitus. Hepatogastroenterology 58:2103-2105

Kaji K, Yoshiji H, Ikenaka Y, Noguchi R, Aihara Y, Douhara A et al (2014) Dipeptidyl peptidase-4 inhibitor attenuates hepatic fibrosis via suppression of activated hepatic stellate cell in rats. J Gastroenterol 49:481-491

Kawamura Y, Ikeda K, Arase Y, Hirakawa M, Hosaka T, Kobayashi M et al (2008) Diabetes enhances hepatocarcinogenesis in noncirrhotic, interferontreated hepatitis $C$ patients. Am J Med 123:951-956

Levy MT, McCaughan GW, Abbott CA, Park JE, Cunningham AM, Muller E et a (1999) Fibroblast activation protein: a cell surface dipeptidyl peptidase and gelatinase expressed by stellate cells at the tissue remodeling interface in Human cirrhosis. Hepatology 29:1768-1778

Li Y, Hansotia T, Yusta B, Ris F, Halban PA, Drucker DJ (2003) Glucagon-like peptide-1 receptor signaling modulates beta cell apoptosis. J Biol Chem 278:471-478

Ludwig J, Viggiano TR, McGill DB, Oh BJ (1980) Non-alcoholic steatohepatitis: mayo Clinic experiences with a hitherto unnamed disease. Mayo Clin Proc 55:434-438

Nauck MA, Meininger G, Sheng D, Terranella L, Stein PP (2007) Efficacy and safety of the dipeptidyl peptidase-4 inhibitor, sitagliptin, compared with the sulfonylurea, glipizide, in patients with type 2 diabetes inadequately controlled on metformin alone: a randomized, double-blind, non-inferiority trial. Diabetes Obes Metab 9:194-205

Omar B, Ahren B (2014) Pleiotropic mechanisms for the glucose-lowering action of DPP-4 inhibitors. Diabetes 63(7):2196-2202 
Piazza GA, Callanan HM, Mowery J, Hixson DC (1989) Evidence for a role of dipeptidyl peptidase IV in fibronectin-mediated interactions of hepatocytes with extracellular matrix. Biochem J 262:327-334

Shlomo SB, Zvibel I, Shnell M, Shlomai A, Chepurko E, Halpern Z et al (2011)

Glucagon-Like Peptide-1 reduces hepatic lipogenesis via activation of AMP-activated Protein Kinase. J Hepatology 54(6):1214-1223
Veldt BJ, Chen W, Heathcote EJ, Wedemayer H, Reichen J, Hofmann WP et al (2008) Increased risk of hepatocellular carcinoma among patients with hepatitis C cirrhosis and diabetes mellitus. Hepatology 47:1856-1862

\section{Submit your manuscript to a SpringerOpen ${ }^{\odot}$} journal and benefit from:

- Convenient online submission

- Rigorous peer review

- Immediate publication on acceptance

- Open access: articles freely available online

- High visibility within the field

- Retaining the copyright to your article

Submit your next manuscript at $\boldsymbol{\wedge}$ springeropen.com 